\title{
Possible semi-circumglobal teleconnection across Eurasia driven by deep convection over the Sahel
}

\author{
Tomoe Nakanishi $^{1} \cdot$ Yoshihiro Tachibana $^{1}$ (D) $\cdot$ Yuta Ando $^{1,2}$ (D)
}

Received: 24 August 2020 / Accepted: 6 May 2021 / Published online: 20 May 2021

(C) The Author(s) 2021

\begin{abstract}
The Sahel region, located between the tropical rainforests of Africa and the Sahara Desert, has rainfall that varies widely from year to year, associated with extremely deep convection. This deep convection, strongly heated by water vapor condensation, suggests the possibility of exerting a remote influence on mid- and high-latitude climate similar to the well-known influences of tropical oceanic convection on global climate. Here we investigate the possibility that deep convection over the Sahel initiates a semi-circumglobal teleconnection extending to eastern Eurasia. Statistical analysis and numerical experiments support the possible existence of this teleconnection at an interannual time scale. We propose that the anomalous heat source due to deep convection over the Sahel in the late monsoon season influences meandering of the mid-latitude jet stream over Europe through the combination of a Matsuno-Gill response and advection of absolute vorticity. This subtropical jet meander may in turn drive an eastward propagation of a Rossby wave across Eurasia as far as East Asia. Because deep convection over other subtropical land areas may exert a similar remote influence upon extratropical extreme weather, further studies of the influence of overland convection may provide us with an expanded comprehension of teleconnections.
\end{abstract}

Keywords Sahel $\cdot$ Convective activity $\cdot$ Teleconnection $\cdot$ Rossby wave $\cdot$ Linear regression

\section{Introduction}

Teleconnection patterns, which usually accompany anomalous jet streams with their anomalous locations or strength, are involved in climate variabilities of atmospheric circulations and their associated extreme weather (e.g., Rodwell and Hoskins 1996, 2001; Wakabayashi and Kawamura 2004). Wakabayashi and Kawamura (2004) and Tachibana et al. (2004) show teleconnections lying across northern Eurasia cause abnormal weather in East Asia in summer. For example, abnormal heat wave in northern Eurasia occurred in early summer 2018. The meandering of polar front jet associated with the propagation of Rossby waves across northern Eurasia have been pointed out as one of the main factors for that abnormal summer (Kornhuber et al.

Yoshihiro Tachibana

tachi@bio.mie-u.ac.jp

1 Weather and Climate Dynamics Division, Faculty of Bioresources, Mie University, 1577 Kurimamachiya-cho, Tsu, Mie 514-8507, Japan

2 Faculty of Science, Niigata University, 8050 Ikarashi 2-no-cho, Nishi-Ku, Niigata, Niigata 950-2181, Japan
2019; Harada et al. 2020). Yasunari et al. (2021) pointed that circum-Arctic atmospheric wave patterns accompanying warm anticyclonic anomalies over Europe and Siberia often induce large-scale wildfires around the Arctic in recent summers. Teleconnections tend to originate where heat of condensation in convection provides an anomalous heat source in the middle troposphere over the tropics (e.g., Hoskins and Karoly 1981; Enomoto et al. 2003). The best-known teleconnections originate in areas of vigorous convective activity over the ocean, which yields large amounts of condensation heat. For example, the remote influences of the El Niño-Southern Oscillation (e.g., Alexander et al. 2002), the Pacific-North American teleconnection pattern (e.g., Mori and Watanabe 2008), the boreal summer intraseasonal oscillation (e.g., Moon et al. 2013), and the Pacific-Japan pattern (Nitta 1987) have been extensively studied. On the other hand, little attention has been paid to the influences of major convection centers over the land upon remote extreme weather. Rodwell and Hoskins (2001) shows teleconnection originating from land rainfall overall, but they did not examine specific remote extreme weather. Although the amount of heating by convection is often smaller over the land than over the ocean, updraft could develop more intensely over 
the land, where the ground surface is easier to warm because its specific heat is smaller than that of seawater. Therefore, the ratio of convective rainfall to stratiform rainfall is high over the land, and cloud tops can reach the upper troposphere more easily than over the ocean (e. g., Schumacher and Houze 2003; Liu and Zipser 2005). There is cooling in lower levels in stratiform rainfall, while in convective rainfall, there is a heat source throughout the troposphere (Schumacher et al. 2004). Such a heat source can be an effective wave source of teleconnections in mid and high latitudes, even when the amount of heat involved is smaller.

This study focused on convection over the Sahel region, the semi-arid southern edge of the Sahara Desert in North Africa. The Sahel owes its distinct rainy (June-September) and dry (October-May) seasons to the West African monsoon (e.g., Nicholson 2013). Convection in the rainy season is extremely deep (Kodera et al. 2019), and it fluctuates widely from year to year (e.g., Nicholson and Palao 1993). Furthermore, the Sahel region is close to the climatological subtropical westerly jet, which can play a role in a waveguide for a teleconnection pattern (Hoskins and Ambrizzi 1993). These factors favor the upper atmosphere over the Sahel as a wave source that may drive a teleconnection with remote mid-latitude locations.

Some studies have suggested that interannual variations in the Sahel convection affect European climate through meandering of the jet (e.g., Black et al. 2004; Cassou et al. 2005; Gaetani et al. 2011). Jet meandering induced by the Sahel convection may propagate beyond Europe owing to a stationary Rossby wave. However, no studies have considered possible teleconnections from the Sahel to more distant regions, although remote influences upon the Sahel rainfall from elsewhere have been extensively examined (e.g., Folland et al. 1986; Munemoto and Tachibana 2012; Diawara et al. 2016). In this study we used statistical analyses and simple numerical experiments to address the possible existence of a semi-circumglobal teleconnection from the Sahel to eastern Eurasia that arises during anomalous heat production by deep convection over the Sahel. Given that the Pacific-Japan teleconnection pattern is known to propagate from low latitudes over the Philippines through Japan to North America (Nitta 1987), we consider it possible that the Sahel convection excites a teleconnection halfway around the world.

\section{Data and methods}

We used the monthly Interpolated Outgoing Longwave Radiation (OLR) dataset from the US National Oceanic and Atmospheric Administration (NOAA) (Liebmann and Smith 1996) as an index of convective activity. This dataset is based on satellite observation, which corresponds to cloud-top temperature in the tropics. The OLR data set is thus widely used as a proxy of tropical convective activity (e.g., Wheeler and Kiladis 1999; Lawrence and Webster 2002). Other atmospheric variables such as geopotential height, vertical velocity, velocity potential, diabatic heating rate, and convective heating rate were obtained from the Japanese 55-year reanalysis (JRA-55) (Kobayashi et al. 2015; Harada et al. 2016). We calculated a global climatological map of convective heating rate, averaged from 1000 to $100 \mathrm{hPa}$ altitude, to assess the strength of the Sahel convection relative to other regions (Fig. 1). Following a previous study (Gaetani et al. 2011), we defined the Sahel as the domain bounded by longitude $20^{\circ} \mathrm{W}-40^{\circ} \mathrm{E}$ and latitude $10^{\circ}$ $\mathrm{N}-20^{\circ} \mathrm{N}$. This region, which is slightly north of the center of strong convective heating, was selected because its interannual variation is greater than at the center (Munemoto and Tachibana 2012; Diawara et al. 2016). However, the results did not strongly depend on the choice of area. The monthly mean Sahelian OLR index is the area-averaged value for the Sahel region. The index values shown in Fig. 2 are linearly detrended, standardized, and multiplied by -1 such that a positive value signifies convective activity that is stronger than normal. We performed a linear regression analysis of large-scale detrended atmospheric fields with the Sahelian OLR index during the rainy season (June through September) of each year from 1979 to 2016. Anomalies based on our regression analyses are referred to as "regressed anomalies" hereafter. The $t$ test was performed for the regressed anomalies and the null hypothesis was rejected when the statistical significance was less than $10 \%$. Although signatures of a wave train pattern appeared in all 4 months, this paper shows the results for September, when the pattern was clearest.

To investigate whether anomalous heat sources from Sahelian convection are capable of driving wave-train patterns, we performed a numerical experiment using a linear baroclinic model (LBM; Watanabe and Kimoto 2000) to compute the steady response of atmospheric fields to a heat source associated with convective activity over the Sahel. The model was run in T42L20 (horizontal resolution of $2.8^{\circ} \times 2.8^{\circ}$ and 20 vertical layers). A heating anomaly reaching $0.5 \mathrm{~K} \mathrm{day}^{-1}$ at its center was applied to the upper troposphere over the western Sahel. Detailed description of the LBM is in Supplemental Information.

\section{Results}

\subsection{Influence of the Sahel convection on large-scale atmospheric circulation}

The climatological map of convective heating rate in September (Fig. 1) shows that the Sahel region ranks among 

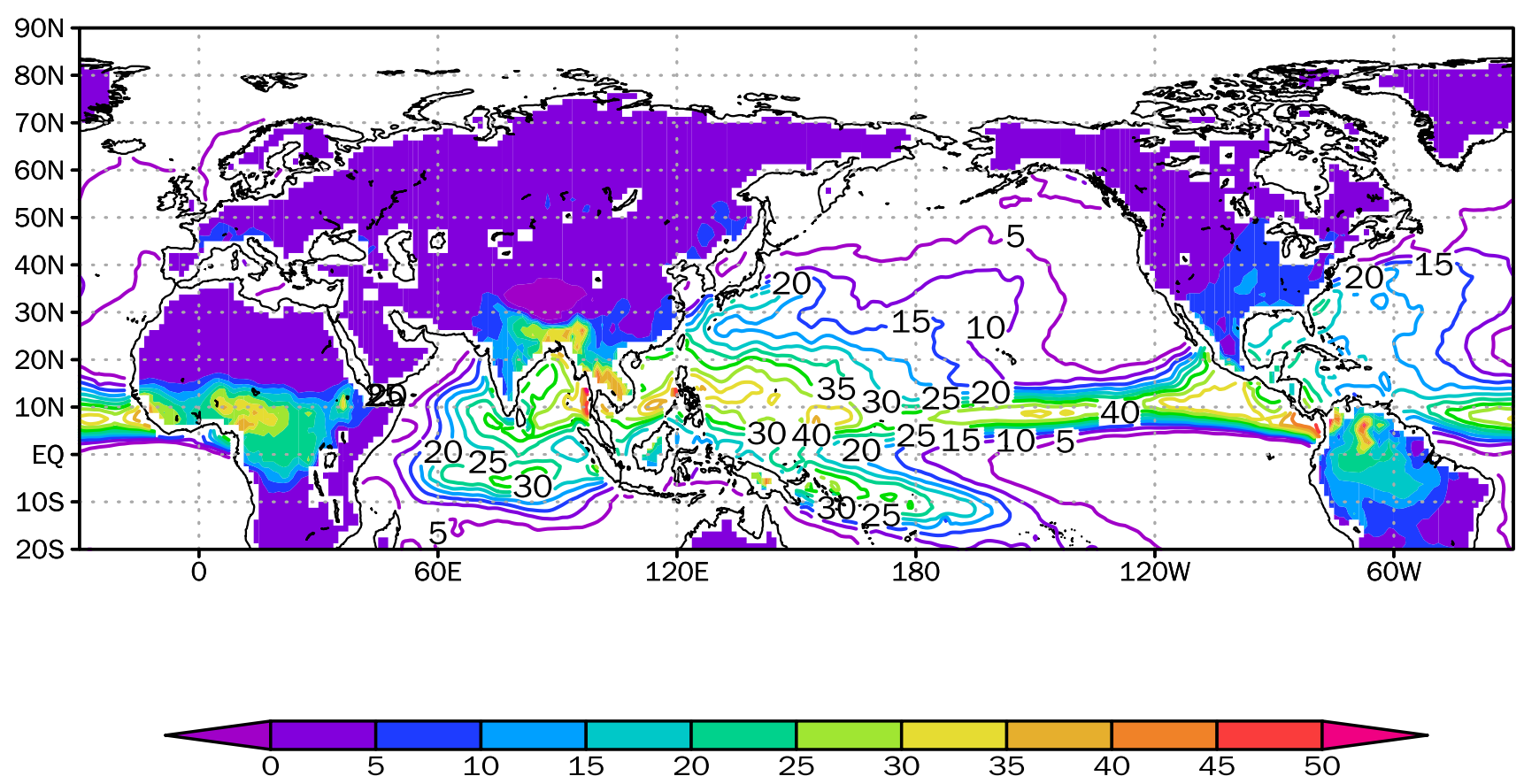

Fig. 1 Climatology of convective heating rates in September (1981-2010 mean). Heating rates for land and sea are shown by color shades and contours, respectively, for visibility. The interval of the shades and contours is $5 \mathrm{~K} \mathrm{day}^{-1}$

Fig. 2 The Sahelian OLR index (blue bars) and the index of our proposed semi-circumglobal teleconnection pattern (Eq. 1; red dots) in September of 19792016. See the text for definitions of these indexes. A linear trend has been removed by linear regression. Note that the sign of the OLR index is reversed, such that a positive value signifies stronger than usual convective activity over the Sahel region

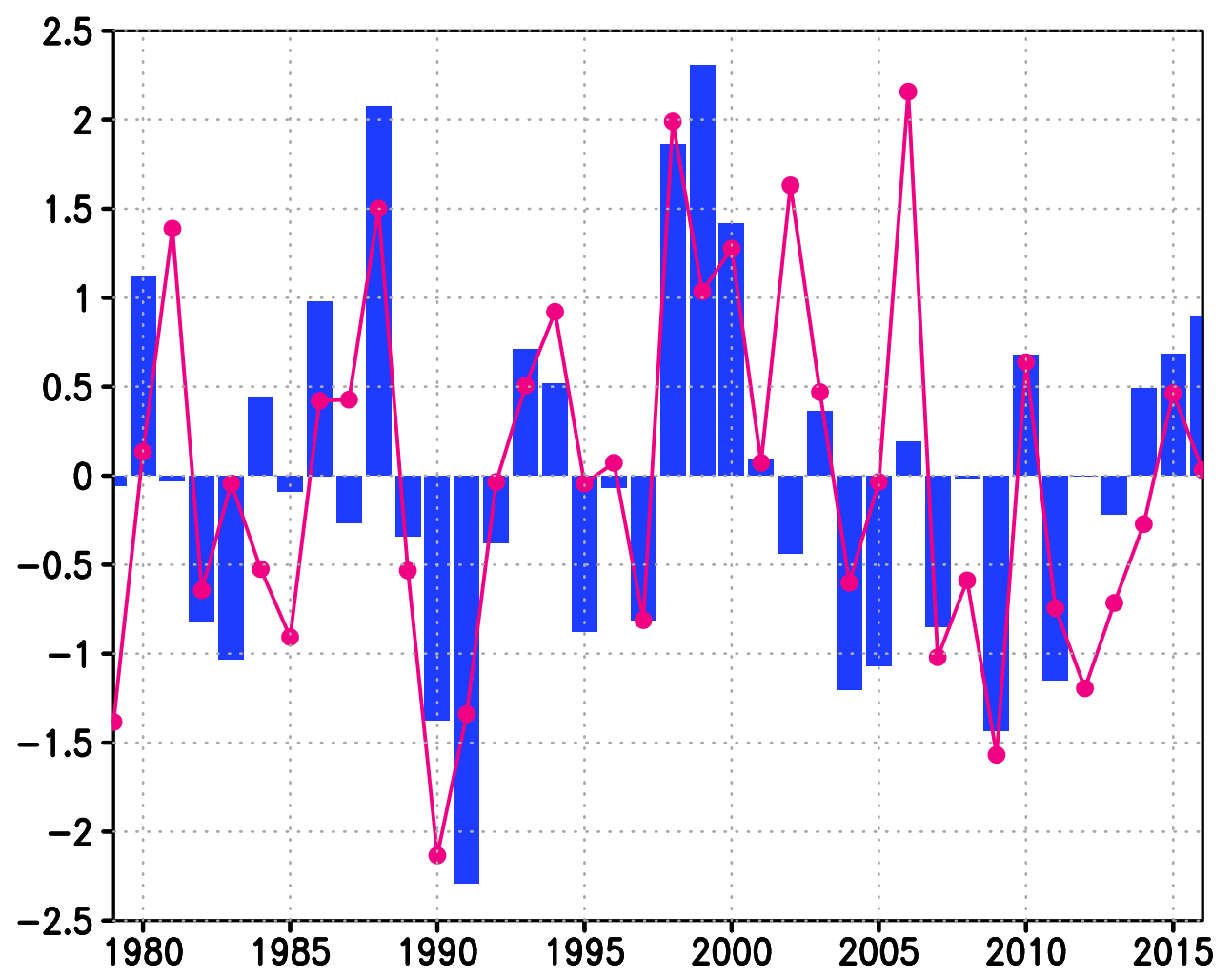

the world's largest areas of convective activity over land. A regression analysis based on the Sahelian OLR index (Fig. 2) was used to calculate the resulting anomalies of
OLR and geopotential height at $300 \mathrm{hPa}$ in September (Fig. 3). Figure 3a shows that negative OLR anomalies appear strongly throughout the Sahel region since the 
(a)

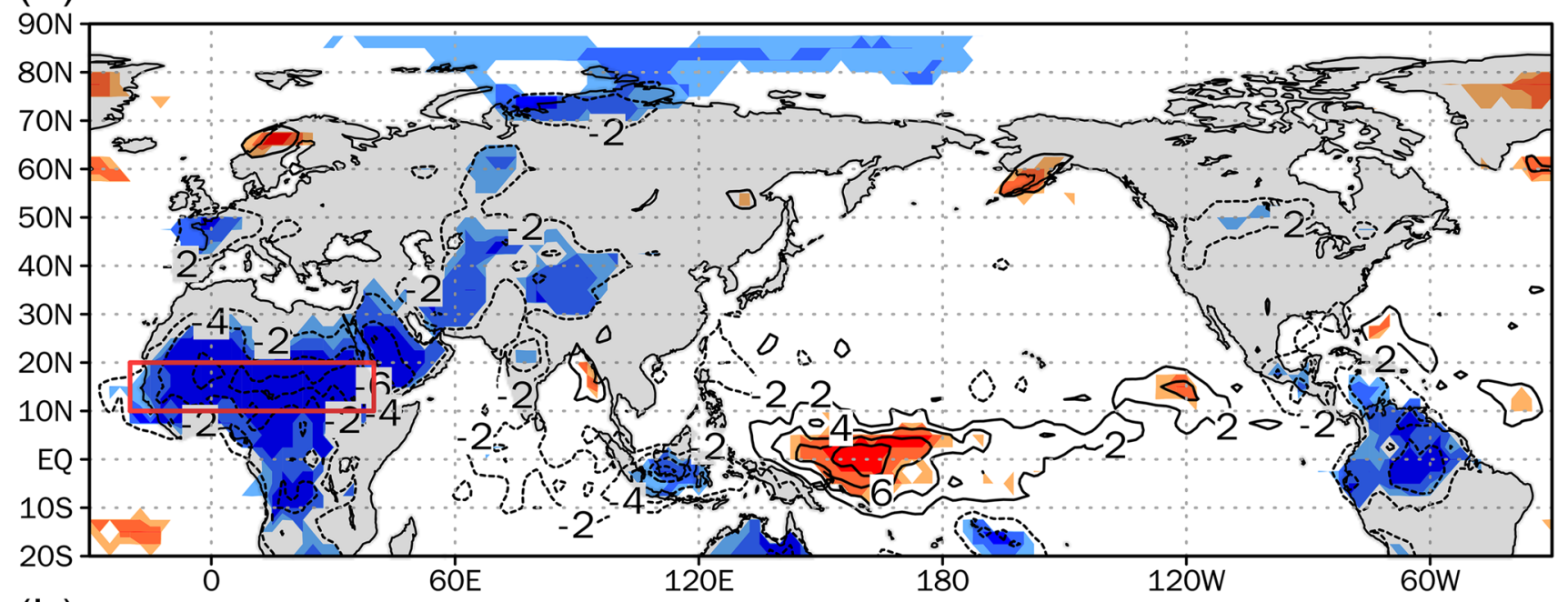

(b)

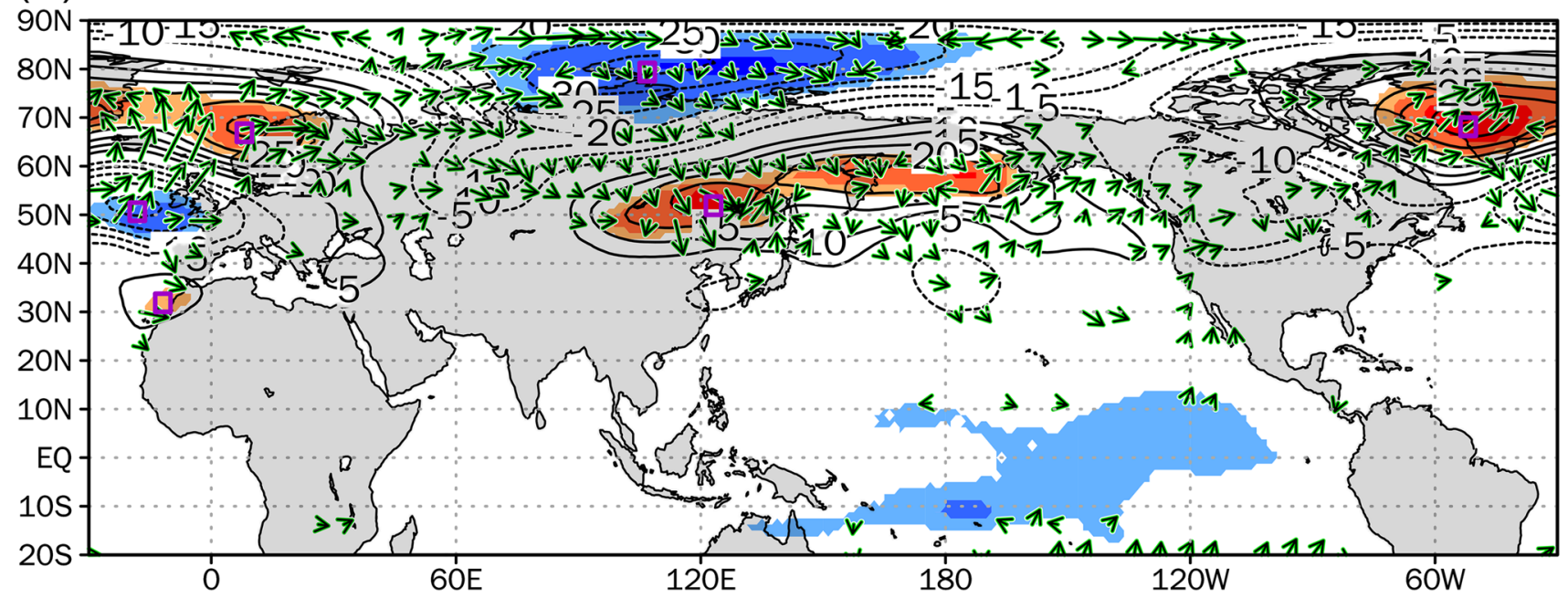

Fig. 3 Maps showing contours of anomalies in a OLR $\left(\mathrm{W} \mathrm{m}^{-2}\right)$ and b geopotential height at $300 \mathrm{hPa}(\mathrm{m})$ regressed against the Sahelian OLR index in September, when convective activity over the Sahel is especially strong. Color shading indicates regions where values satisfy less than $10 \% 5 \%$, and $1 \%$ levels of statistical significance by $t$-test. The red rectangle in a outlines the area where the Sahel OLR index is calculated. Six purple rectangles in $\mathbf{b}$ outlines the area where the semi-circumuglobal teleconnection index is calculated. Vectors in b indicate wave activity flux $\left(\mathrm{m}^{2} \mathrm{~s}^{-2}\right)$

agreement with a Sahel-excited pattern reported in a previous study (Gaetani et al. 2011). In addition, a second cyclonic anomaly appears over Siberia and an anticyclonic anomaly appears to the north of Japan. These anomalies constitute a wave train pattern that extends from Europe 
to East Asia. When the convective activity over the Sahel is anomalously strong, high-pressure anomalies in the upper troposphere cover the Canary Islands, Scandinavia, and northeast Asia, and low-pressure anomalies cover the British Isles and the polar region. To indicate the scale of this anomaly pattern, we refer to it as a semi-circumglobal teleconnection pattern. We define the index of this teleconnection pattern from anomalies at four action centers shown in Fig. $3 \mathrm{~b}$ as follows: coefficient of 0.66 between the semi-circumglobal teleconnection index and the OLR index, which satisfies less than $1 \%$ levels of statistical significance by $t$ test, indicated that the variations in the two indexes are synchronized in most years.

To visualize the propagation of the stationary Rossby wave, we plotted the vectors of wave activity flux (Takaya and Nakamura 2001) in Fig. 3, which clearly trace Rossby wave propagation from Europe to East Asia. This transcon-

$$
\begin{aligned}
\text { semi-circumglobalteleconnectionindex }= & {\left[\text { ave } Z_{300}\left(10.00^{\circ}-13.75^{\circ} \mathrm{W}, 30.00^{\circ}-33.75^{\circ} \mathrm{N}\right)\right.} \\
& -\operatorname{aveZ}_{300}\left(16.25^{\circ}-20.00^{\circ} \mathrm{W}, 48.75^{\circ}-52.50^{\circ} \mathrm{N}\right) \\
& +\operatorname{aveZ}_{300}\left(6.25^{\circ}-10.00^{\circ} \mathrm{E}, 65.00^{\circ}-68.75^{\circ} \mathrm{N}\right) \\
& +\operatorname{aveZ}_{300}\left(50.00^{\circ}-53.75^{\circ} \mathrm{W}, 66.25^{\circ}-70.00^{\circ} \mathrm{N}\right) \\
& -\operatorname{aveZ}_{300}\left(105.00^{\circ}-108.75^{\circ} \mathrm{E}, 77.50^{\circ}-81.25^{\circ} \mathrm{N}\right) \\
& \left.+\operatorname{aveZ}_{300}\left(121.25^{\circ}-125.00 \mathrm{E}, 50.00^{\circ}-53.75^{\circ} \mathrm{N}\right)\right] / 6
\end{aligned}
$$

where ave $Z_{300}$ indicate area averaged values in defined rectangles of geopotential height at $300-\mathrm{hPa}$. The rectangles are $10.00^{\circ}-13.75^{\circ} \mathrm{W}, 30.00^{\circ}-33.75^{\circ} \mathrm{N}$ for the Canary Islands, $16.25^{\circ}-20.00^{\circ} \mathrm{W}, 48.75^{\circ}-52.50^{\circ} \mathrm{N}$ for the British Isles, $6.25^{\circ}-10.00^{\circ} \mathrm{E}, 65.00^{\circ}-68.75^{\circ} \mathrm{N}$ for Scandinavia, $50.00^{\circ}-53.75^{\circ} \mathrm{W}, 66.25^{\circ}-70.00^{\circ} \mathrm{N}$ for Greenland, $105.00^{\circ}-108.75^{\circ} \mathrm{E}, 77.50^{\circ}-81.25^{\circ} \mathrm{N}$ for the polar region and $121.25^{\circ}-125.00^{\circ} \mathrm{E}, 50.00^{\circ}-53.75^{\circ} \mathrm{N}$ for East Asia. The index is overlaid with red dots in Fig. 2. The correlation tinental wavy pattern over northern Siberia accords with the conditions favoring the appearance of the Okhotsk high (Nakamura and Fukamachi 2004; Tachibana et al. 2004).

We further examined the possibility that the tropical ocean influences this teleconnection, as suggested by a significant correlation between the Sahelian OLR index and some areas of the tropical Pacific Ocean and Atlantic Ocean (Fig. S1, e.g., Rodríiguez-Fonseca et al. 2015). However, we confirmed that the semi-circumglobal teleconnection pattern still persisted (Figs. S2a and S2b) when these oceanic effects (a)

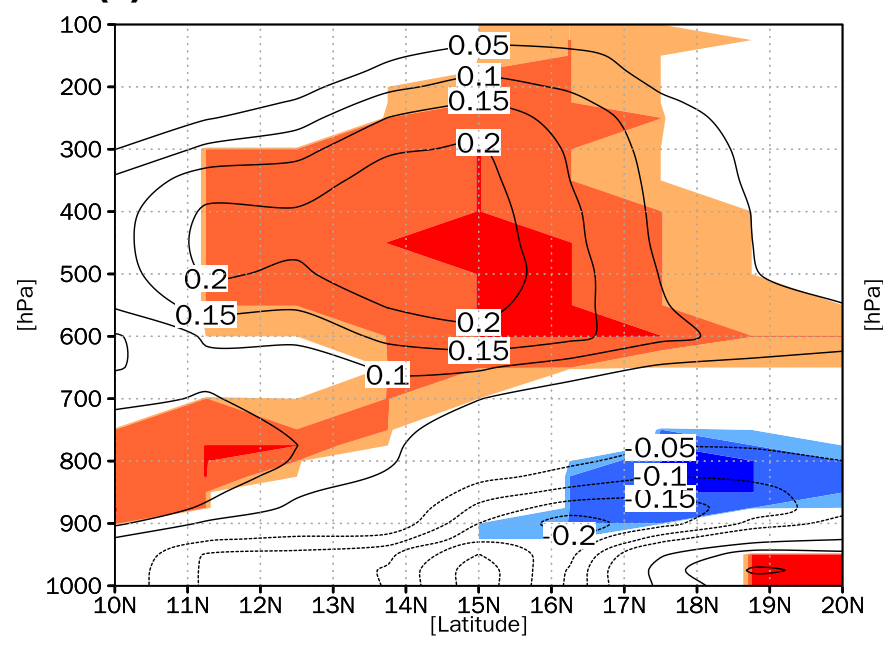

Fig. 4 Latitude-height cross sections of the Sahel model region showing contours of longitudinally averaged values $\left(20^{\circ} \mathrm{W}-40^{\circ} \mathrm{E}\right)$ of a diabatic heating $\left(\mathrm{K} \mathrm{day}^{-1}\right)$ and $\mathbf{b}$ vertical velocity $\left(\mathrm{Pa} \mathrm{s}^{-1}\right)$ regressed against the Sahelian OLR index in September. Color shading indi- (b)

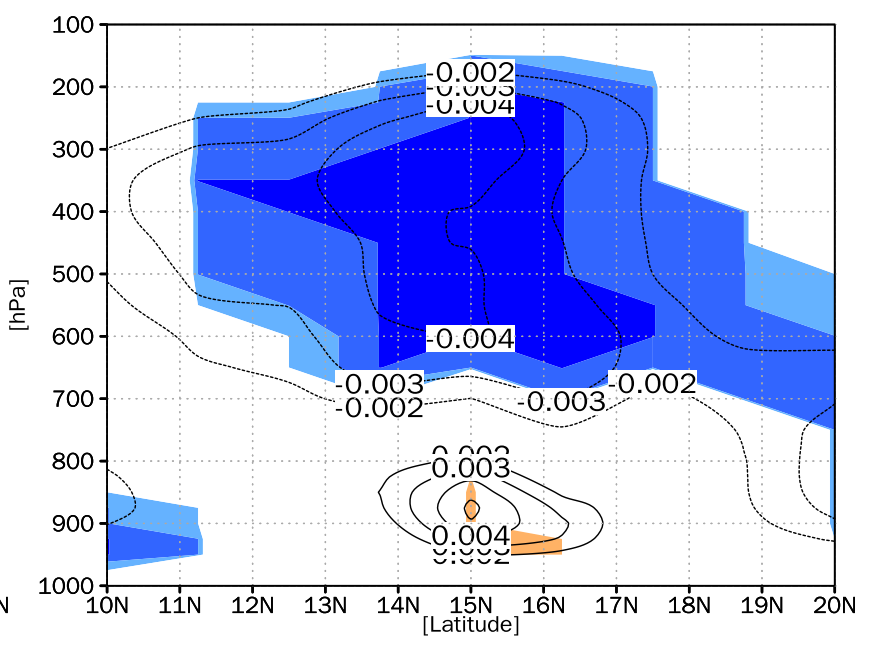

cates regions where values satisfy less than $10 \% 5 \%$, and $1 \%$ levels of statistical significance by $t$ test. Note that positive values signify positive heating in $\mathbf{a}$ and downdraft anomalies in $\mathbf{b}$ 
Fig. 5 Regional map showing contours of anomalies in stream functions $\left(\times 10^{5} \mathrm{~m}^{2} \mathrm{~s}^{-1}\right)$ at a 300 $\mathrm{hPa}$ and $\mathbf{b} 850 \mathrm{hPa}$ regressed against the Sahelian OLR index in September. Color shading indicates regions where values satisfy less than $10 \% 5 \%$, and $1 \%$ levels of statistical significance by $t$ test
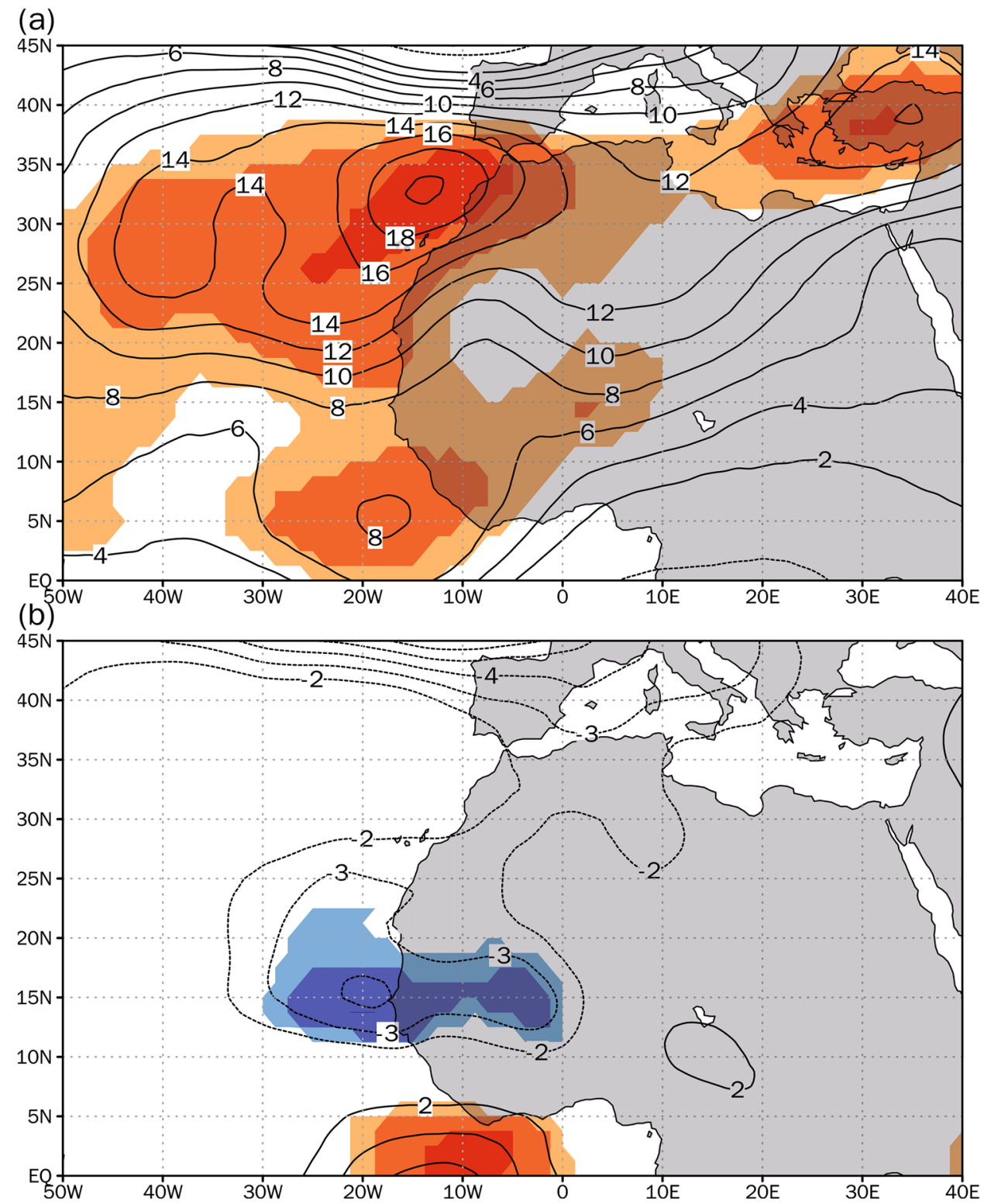

were removed by a linear regression method (e.g., Kodera et al. 1999). Detailed description of these analysis is in Supplemental Information. We also examined linear regressed sea surface temperature (SST) and OLR fields with the semicircumglobal teleconnection index (Eq. 1) by a similar manner to the Sahelian OLR index. The regressed maps did not show any significant signals in tropical-subtropical regions other than the Sahel with the exception of OLR in the tropical western Pacific (not shown). This signal also appears in Fig. 3a. Coherent variations between Sahel and the tropical western Pacific implies that Sahel convection is partially strengthened by or strengthens the tropical western Pacific through the Walker circulation. The coherent variations with the tropical Pacific is seen over specific parts of the Sahel (Fig. S3). Thus, the tropical western Pacific does not directly excite the semi-circumglobal teleconnection pattern, neither does the SST in the western tropical Pacific. Therefore, the relationship between convective activity over the Sahel and the wave train pattern is not caused by the tropical ocean alone.

\subsection{Mechanism of formation of anticyclonic anomaly northwest of the Sahel}

Whereas the previous subsection delineated the propagation of a Rossby wave from Europe to East Asia, here we 
discuss a possible mechanism of the formation of the anticyclonic anomaly over the Azores, the starting point of the wave propagation: a combination of the Matsuno-Gill pattern (Matsuno 1966; Gill 1980) and vorticity forcing. First, we consider the longitudinally averaged atmospheric vertical fields over the Sahel. Figure 4 shows anomalous positive diabatic heating and updrafts in the middle troposphere above $600 \mathrm{hPa}$, forming a classic Matsuno-Gill pattern. Figure 5 shows that regressed anomalies of the stream function are anticyclonic in the upper troposphere $(300 \mathrm{hPa})$ and cyclonic in the lower troposphere $(850 \mathrm{hPa})$ over the region northwest of the Sahel. This pattern is consistent with the Matsuno-Gill pattern when the heat source is located off the equator. Figure 6 shows a global plot of regressed anomalies of velocity potential and divergent wind at $200 \mathrm{hPa}$. That depicts a northwestward divergent wind north of the Sahel. Interpreting this feature in terms of the mechanism of advection of absolute vorticity (e.g. Sardeshmukh and Hoskins 1988), this northwestward wind is transporting a negative vorticity anomaly from the equatorial region to the subtropics. The calculation of Rossby wave source by Sardeshmukh and Hoskins (1988) supported that the negative vorticity advection is a main factor in the northwest of the Sahel region (not shown). Thus, the anticyclonic anomaly is generated in the upper troposphere northwest of the Sahel shown in Fig. 5b. Since some studies have already shown the influence of Sahel convection upon European climate through meandering of the jet (e.g., Black et al. 2004; Cassou et al. 2005; Gaetani et al. 2011), the Sahel-Europe teleconnection can be acceptable.

\subsection{Linear baroclinic model (LBM) experiment}

We conducted a numerical experiment using a LBM to verify whether the anomalous heat source due to convection over the Sahel could drive teleconnection patterns. The results of our regression analysis using the Sahelian OLR index showed that diabatic heating reaches its maximum over the western Sahel in the middle troposphere at $400 \mathrm{hPa}$ (Fig. 7a, b). We then used this regressed anomaly pattern as the heat forcing in the LBM, which reached a maximum value of about $0.5 \mathrm{~K} \mathrm{day}^{-1}$ at the center of the anomaly (Fig. 7c, d). The model experiment yielded a clear wave-like response emitted from the Sahel region at the 300-hPa level (Fig. 8), although its amplitude is smaller than the result of the regression analysis (Fig. 3). Both results show an anticyclonic anomaly northwest of the Sahel, a cyclonic anomaly in southwestern Europe, and an anticyclonic anomaly in northern Europe. This consistency implies that convective activity over the Sahel can trigger the formation of a wave train pattern over Europe. There are other significant large heating areas over the Atlantic Ocean and the East Sahel (Fig. 7a). However, we could not confirm that these heat sources drive the wave train pattern by the additional LBM experiments in which heat forcings are given over these two areas (not shown).

There is a tiny transmission from North Atlantic towards Canary Islands in Fig. 3, which indicates that Sahelian convection may be affected by mid-latitude wave activity. However, there is a certain influence of Sahel upon the mid-latitude wave propagation in the LBM experiments. Actually, there may be a two-way interaction between the Sahelian

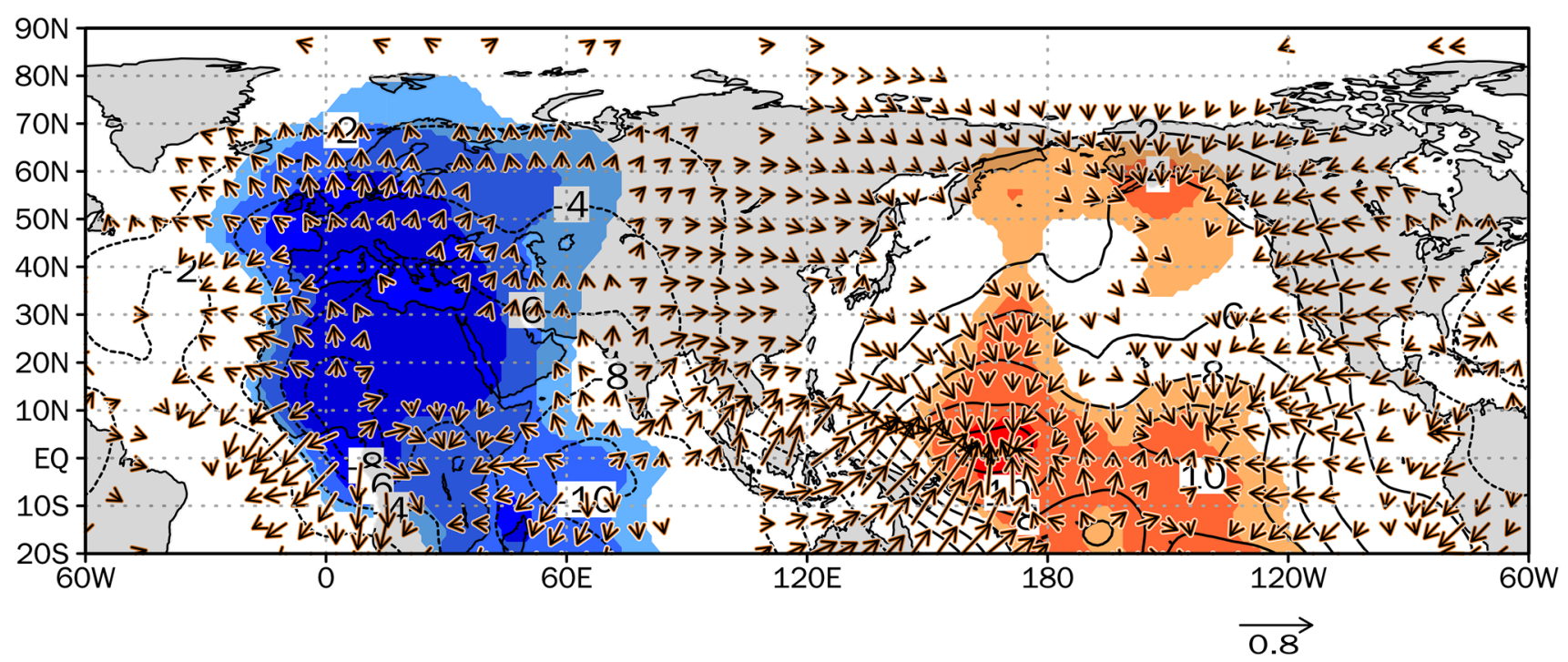

Fig. 6 Map showing contours of anomalies in velocity potential $\left(\times 10^{5} \mathrm{~m}^{2} \mathrm{~s}^{-1}\right)$ at $200 \mathrm{hPa}$ regressed against the Sahelian OLR index in September. Blue and red colors indicate regions of divergence and convergence, respectively, where values satisfy less than $10 \% 5 \%$, and $1 \%$ levels of statistical significance by $t$ test. Vectors indicate divergent winds $\left(\mathrm{m} \mathrm{s}^{-1}\right)$ 
(a)

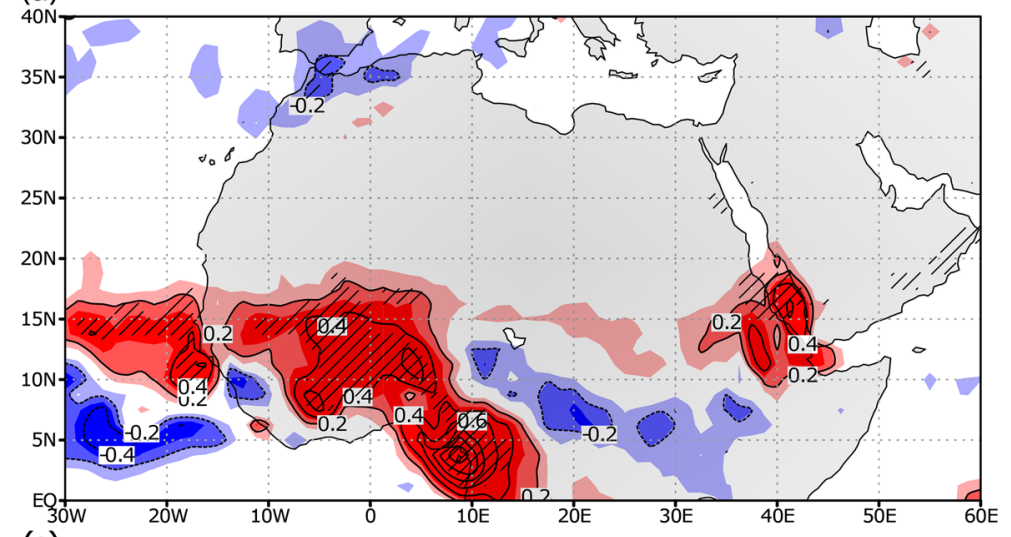

(c)

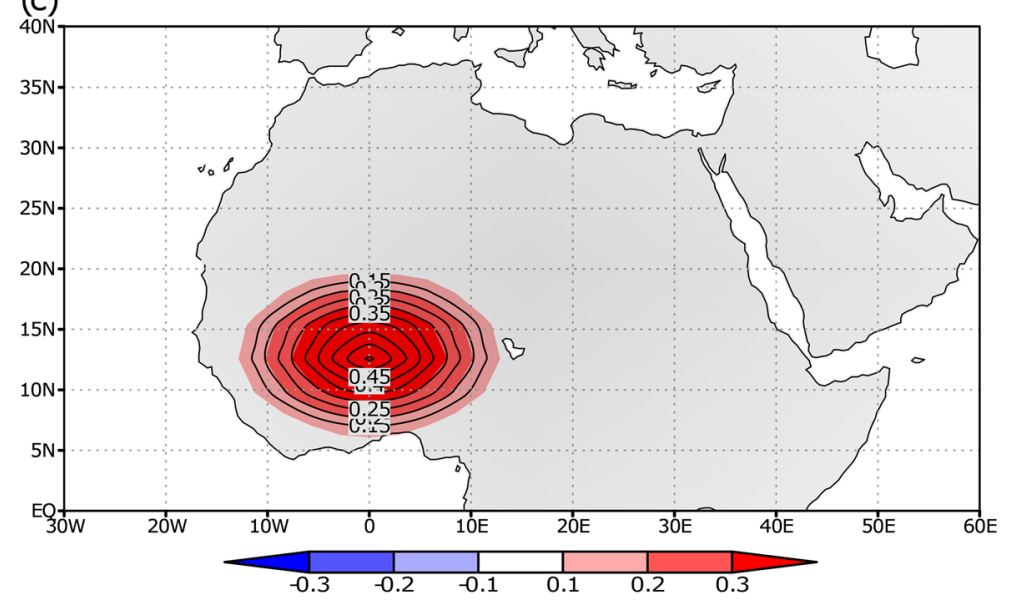

(b)

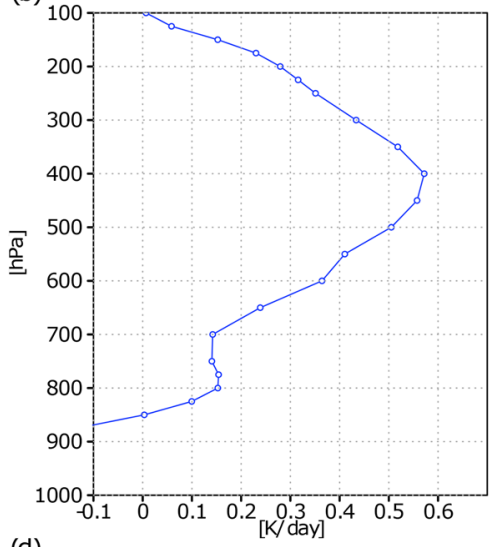

(d)

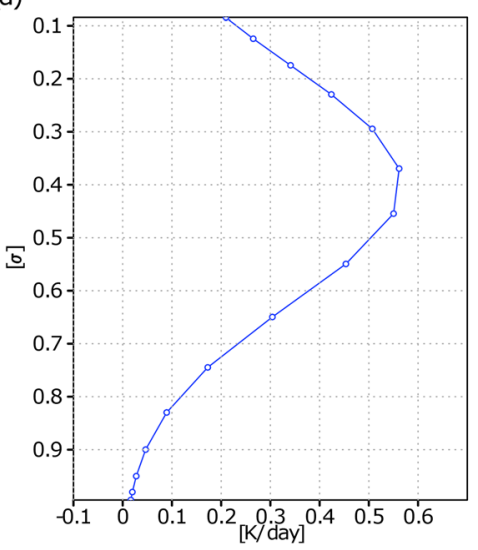

Fig. 7 a Regional map of regressed diabatic heating rate $\left(\mathrm{K} \mathrm{day}^{-1}\right)$ at $400 \mathrm{hPa}$ (contours and shading). Hatching indicates areas where values satisfy less than $10 \%$ level of statistical significance by $t$ test. b

convection and mid-latitude wave activity. This may amplify the Sahel convection that further influences upon the midlatitude wave train.

\section{Discussion}

Our experiments suggest that the interannual variability of the Sahelian convection drives a semi-circumglobal teleconnection across Eurasia. The implication is that Sahelian convection may be as important as the oceanic convective activity that drives the Pacific-Japan and Pacific-North American teleconnections. Although the influence of continental convection is given less attention than the predominant influence of oceanic convection, the condensation heating over Sahel is exceptionally large for a continental area (see Fig. 1). As we described earlier, the relationship between the Sahelian convection and the wave train pattern is not caused by the tropical ocean alone. Here we explore the details of the proposed teleconnection.
Vertical profile at $0^{\circ} \mathrm{E}, 13^{\circ} \mathrm{N}$, the center of the large positive heat signature in $\mathbf{a} . \mathbf{c}$ and $\mathbf{d}$ same as $\mathbf{a}$ and $\mathbf{b}$ but for the heating rate given in a LBM experiment

Figure 9 shows the schematics of the proposed teleconnection. Enhanced Sahelian convective activity associated with heavy monsoon rainfall strengthens diabatic heating with updraft in the middle troposphere (Fig. 4). The anomalous heat source activates an anticyclonic anomaly in the upper troposphere northwest of the Sahel by the MatsunoGill mechanism (Fig. 5), like those seen in other subtropical areas over the ocean (e.g., Wang et al. 2000; Yang et al. 2007). In addition, a divergent wind driven by this heat source creates a northward wind component in the upper troposphere northwest of the Sahel that results in northward advection of absolute vorticity (Fig. 6). The wavy pattern from the Sahel to Europe is consistent with the results of a LBM that incorporates the anomalous heat source over the Sahel (Fig. 8). The wave's arrival over Europe may act as a further wave source for the eastward propagation of stationary Rossby waves along the polar front jet stream over northern Eurasia (Fig. 3b).

We further conducted an additional LBM experiment in which negative vorticity forcing is given to the west of Norway (Figs. S4a and S4b) in order to examine whether 

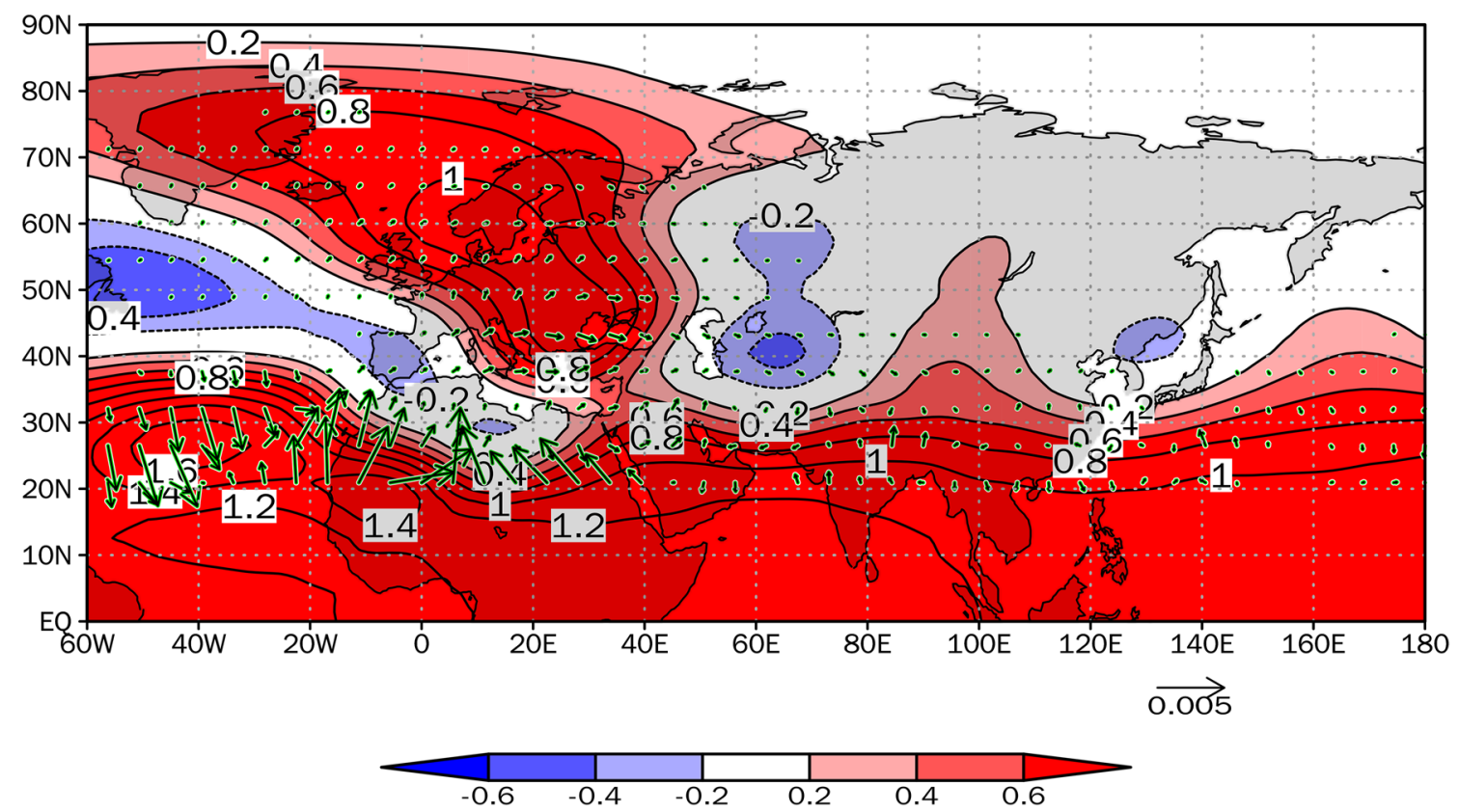

Fig. 8 Steady-state response to the heating anomaly in the LBM experiment. Contours and colors indicate anomalies of 300-hPa geopotential height $(\mathrm{m})$, and vectors indicate wave activity flux $\left(\mathrm{m}^{2} \mathrm{~s}^{-2}\right)$

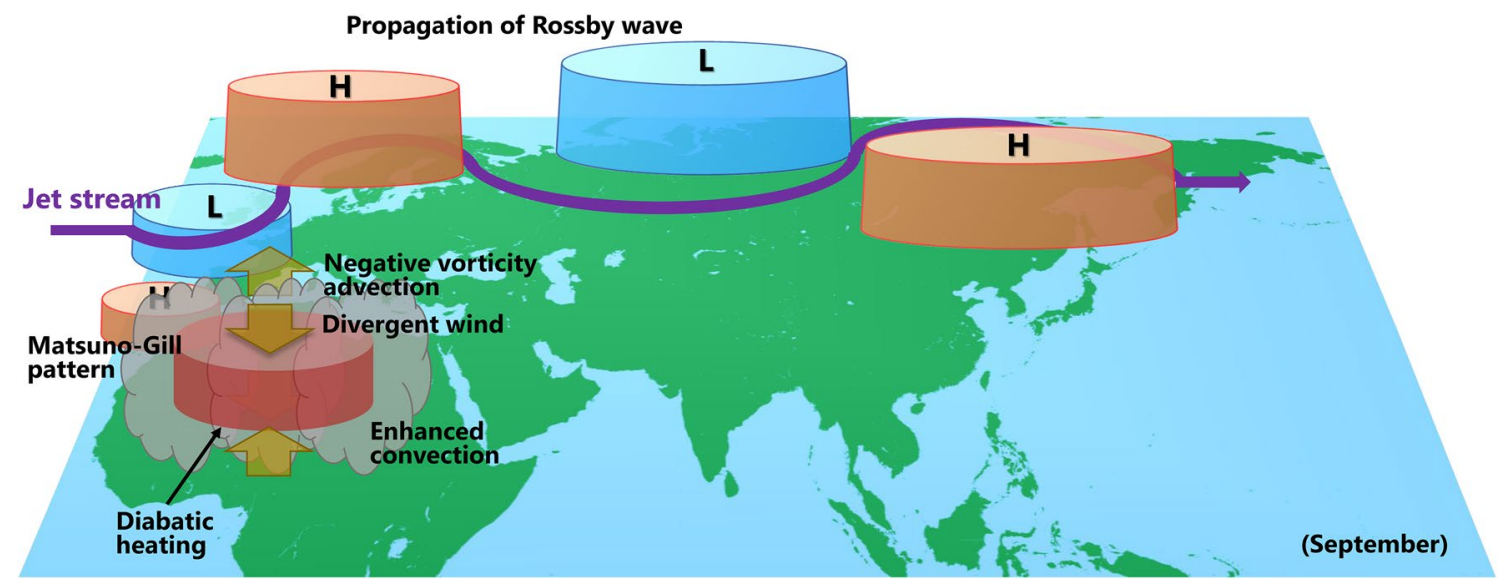

Fig. 9 Schematic diagram of proposed semi-circumglobal teleconnection driven by deep convection over the Sahel

anomalies over Europe can be a wave source of eastward propagation. Given negative vorticity corresponds to the anticyclonic anomaly shown in regression analysis (Fig. 3b) and the LBM experiment (Fig. 8). Responding atmospheric circulations show an anticyclonic anomaly west of Norway, a cyclonic anomaly in the polar region, and an anticyclonic anomaly over East Asia (Fig. S5). These are approximately consistent with the semi-circumglobal teleconnection pattern shown in Fig. 3b. The responding semi-sircumglobal wave pattern did not clearly appear as direct response to the Sahel convection (Fig. 8), probably because LBM does not include nonlinear feedback. Northward extension of divergent wind to Europe shown in Fig. 6 is a favorable condition for generating an additional Rossby wave source over Europe, because the divergent wind results in northward advection of absolute vorticity.

The propagation of the wave from the Sahel to East Asia may rely on the polar jet, which is known to act as a waveguide in the propagation of a Rossby wave packet (e.g., Nakamura and Fukamachi 2004; Tachibana et al. 2010). Wave propagation eastward along the polar jet over northern Eurasia is occasionally seen in summer when the polar jet stream is strong (e.g., Ogi et al. 2005; Ogasawara and Kawamura 2007; Otomi et al. 2013; Sato and Nakamura 2019). 
(a)

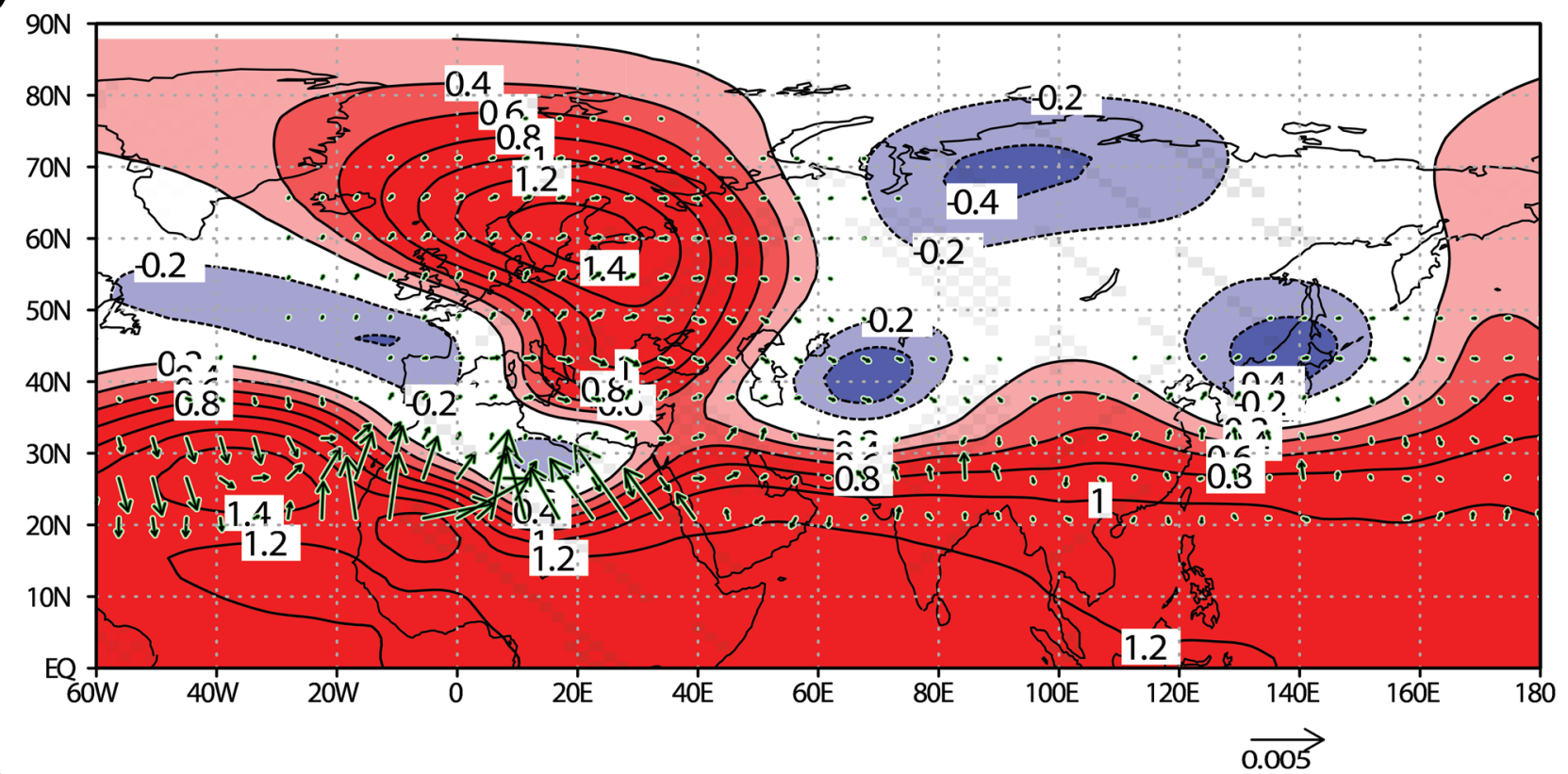

(b)

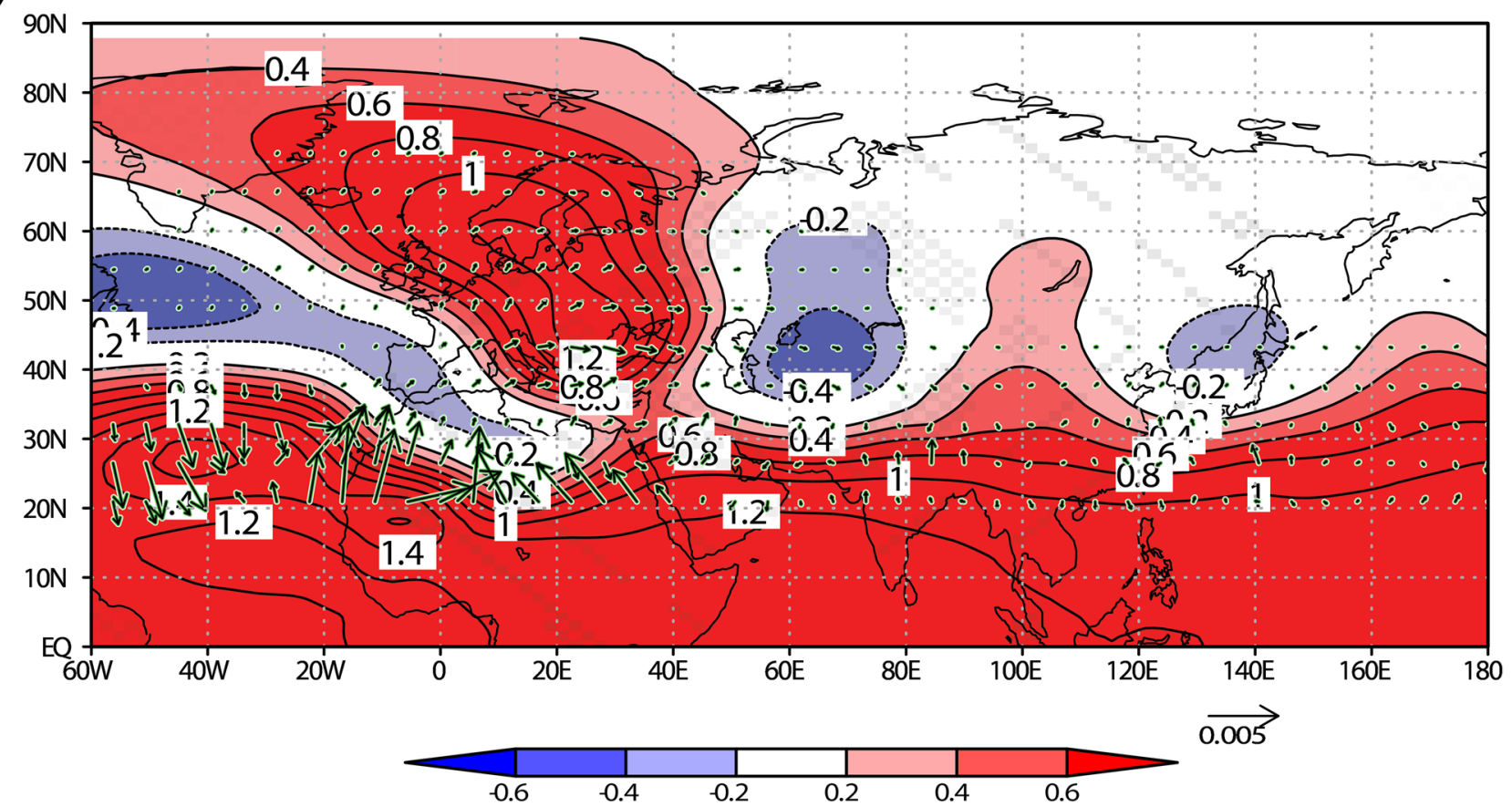

Fig. 10 Steady-state response to the heating anomaly in LBM experiments under two background states; a strong polar jets and $\mathbf{b}$ weak polar jets. The given heating rate is the same as in Fig. $7 \mathrm{c}, \mathrm{d}$. Con-

Sato and Nakamura (2019) shows atmosphere-land interactions over northern Eurasia amplify the transcontinental wave. Otomi et al. (2013) showed that such a transcontinental wave accounted for the abnormally hot summer of 2010 in Russia and East Asia. They also showed that tropical tours and colors indicate anomalies of 300-hPa geopotential height $(\mathrm{m})$, and vectors indicate wave activity flux $\left(\mathrm{m}^{2} \mathrm{~s}^{-2}\right)$

convective activity associated with anomalous oceanic temperatures in the Atlantic Ocean played a role in activating that transcontinental wave. Given Sahel's position east of the Atlantic Ocean, the Sahel convection may play a similar role. Thus, we argue that anomalous convection over the Sahel is 
able to activate a transcontinental wave that produces abnormal weather in Russia and even East Asia. Active Sahel convection that coincides with stronger-than-normal polar jets would strengthen the propagation of the wave to East Asia because strong polar jets act as a waveguide. Similar eastward wave propagation excited by a tropical heat source is recognized over the mid-latitude North Pacific Ocean (e.g., Jin and Hoskins 1995; Nitta and Hu 1996).

We moreover conducted additional LBM experiments with two types of background states in order to examine dependence on the strength of the polar jets. One is the state when the polar jet is strong and the other is weak. We used the Arctic Oscillation (AO) Index defined by Ogi et al. (2004) as an index of the strength of the polar jet. We defined that background mean fields of the top 10 years of the AO index as the strong jet state, and those of the bottom 10 years as the weak jet state. The given heating rate is the same as in Fig. 7c, d. The results imply that the wave train pattern is more likely to propagate eastward when the background polar jet is strong (Fig. 10a) than when it is weak (Fig. 10b).

Small amplitude in the LBM experiment shown in Fig. 8 can be partially attributed to the underestimation of diabatic heat in the reanalysis data set over the tropical convective regions. Kodera et al. (2019) shows that convection in Sahel is extremely deep with strong updraft. Deep convection tends to occur in a narrow region. Another reason is that non-linear effects are not included in the LBM. These may be also responsible for slight differences of anomaly centers of the LBM from those of regression anomalies.

Whereas we presented results for September, when this wave pattern is clearest, the wave pattern was also apparent in June, July and August. We suggest that September has a favorable condition for the propagation of Rossby waves in this region because the latitude belts of westerly wind shifts southward as the progress of the summer season, which is favorable for the wave propagation. Regression maps with the Sahelian OLR index in other months are in Fig. S6a-S6d for reference.

\section{Summaries}

In summary, this study has demonstrated the possible existence of a semi-circumglobal teleconnection from the Sahel to East Eurasia. The teleconnection relies on a causal link between two atmospheric waves, one a wave from the subtropics to mid-latitudes, the other a Rossby wave propagation along the polar jet. The details of that link are beyond the scope of this study, but should be examined in the future. It should be noted that the Sahel convection plays a role in amplifying an existing semi-circumglobal teleconnection.

We speculate that some extreme weather events in mid latitudes, such as the extreme hot summer in East Asia in
2018, might be influenced by abnormal convection in the Sahel. The wave train pattern clearly appeared in the Northern Hemisphere in that year (see Supplementary Information and Fig. S7), and convective activity over the Sahel was more active than the climatological mean (Fig. S8). It could be valuable to extend the analysis presented in this paper to other months and other abnormal years.

Referring again to Fig. 1, areas of strong cloud convection lie over other continental regions, such as South America and the Indochina Peninsula. It seems possible that deep convection over other subtropical continental regions may also exert remote influences upon extreme weather in extratropical localities. Further studies of the influence of convection in continental regions may provide us with an expanded comprehension of teleconnections.

Supplementary Information The online version contains supplementary material available at https://doi.org/10.1007/s00382-021-05804-x.

Acknowledgements We thank Dr. Kunihiko Kodera and Dr. Kazuaki Nishii for insightful discussions. Graduate students at Mie University offered us fruitful advice. We thank anonymous reviewers for their valuable comments and suggestions that improved the quality of the paper. The Grid Analysis and Display System (GrADS) was used to draw the figures.

Funding This study was supported by the Ministry of Education, Culture, Sports, Science and Technology (MEXT) through a Grantin-Aid for Scientific Research on Innovative Areas (Grant numbers 16K13880, 17H02958, 17H01156, 17K01223, 19H05698, 19H05668, and 20K12197), and through the Arctic Challenge for Sustainability (ArCS; JPMXD1300000000) project and its successor project (ArCS II; JPMXD1420318865).

Availability of data and material The JRA-55 reanalysis data and OLR data used during this study are openly available from https://jra.kishou. go.jp/JRA-55/ and https://psl.noaa.gov/data/gridded/data.interp_OLR, respectively. The numerical experiment data used in this study are available from the corresponding author upon request.

\section{Declaration}

Conflict of interest The authors declare no competing financial interests in relation to the work described. The authors declare no competing non-financial interests as well.

Open Access This article is licensed under a Creative Commons Attribution 4.0 International License, which permits use, sharing, adaptation, distribution and reproduction in any medium or format, as long as you give appropriate credit to the original author(s) and the source, provide a link to the Creative Commons licence, and indicate if changes were made. The images or other third party material in this article are included in the article's Creative Commons licence, unless indicated otherwise in a credit line to the material. If material is not included in the article's Creative Commons licence and your intended use is not permitted by statutory regulation or exceeds the permitted use, you will need to obtain permission directly from the copyright holder. To view a copy of this licence, visit http://creativecommons.org/licenses/by/4.0/. 


\section{References}

Alexander MA, Bladé I, Newman M et al (2002) The atmospheric bridge: the influence of ENSO teleconnections on air-sea interaction over the global oceans. J Clim 15:2205-2231. https://doi.org/ 10.1175/1520-0442(2002)015\%3c2205:TABTIO\%3e2.0.CO;2

Black E, Blackburn M, Harrison G et al (2004) Factors contributing to the summer 2003 European heatwave. Weather 59:217-223. https://doi.org/10.1256/wea.74.04

Cassou C, Terray L, Phillips AS (2005) Tropical Atlantic influence on European heat waves. J Clim 18:2805-2811. https://doi.org/10. 1175/JCLI3506.1

Diawara A, Tachibana Y, Oshima K et al (2016) Synchrony of trend shifts in Sahel boreal summer rainfall and global oceanic evaporation, 1950-2012. Hydrol Earth Syst Sci 20:3789-3798. https://doi. org/10.5194/hess-20-3789-2016

Enomoto T, Hoskins BJ, Matsuda Y (2003) The formation mechanism of the Bonin high in August. Q J R Meteorol Soc 129:157-178. https://doi.org/10.1256/qj.01.211

Folland C, Palmer T, Parker D (1986) Sahel rainfall and worldwide sea temperatures, 1901-85. Nature 320:602-607. https://doi.org/ $10.1038 / 320602 \mathrm{a} 0$

Gaetani M, Pohl B, Douville H, Fontaine B (2011) West African Monsoon influence on the summer Euro-Atlantic circulation. Geophys Res Lett 38:38-42. https://doi.org/10.1029/2011GL047150

Gill A (1980) Some simple solutions for heat-induced tropical circulation. Q J R Meteorol Soc 106:447-462. https://doi.org/10.1256/ smsqj.44904

Harada Y, Kamahori H, Kobayashi C et al (2016) The JRA-55 reanalysis: representation of atmospheric circulation and climate variability. J Meteorol Soc Jpn 94:269-302. https://doi.org/10. 2151/jmsj.2016-015

Harada Y, Endo H, Takemura K (2020) Characteristics of large-scale atmospheric fields during heavy rainfall events in western Japan: comparison with an extreme event in early July 2018. J Meteorol Soc Jpn 98:1207-1229. https://doi.org/10.2151/jmsj.2020-062

Hoskins BJ, Ambrizzi T (1993) Rossby wave propagation on realistic longitudinally varying flow. J Atmos Sci 50:1661-1671. https:// doi.org/10.1175/1520-0469(1993)050\%3C1661:RWPOAR\% 3E2.0.CO;2

Hoskins BJ, Karoly D (1981) The steady linear response of aspherical atmosphere to thermal and orographic forcing. J Atmos Sci 38:1179-1196. https://doi.org/10.1175/1520-0469(1981)038\% 3c1179:TSLROA\%3e2.0.CO;2

Jin F, Hoskins BJ (1995) The direct response to tropical heating in a baroclinic atmosphere. J Atmos Sci 52:307-319. https://doi.org/ 10.1175/1520-0469(1995)052\%3c0307:TDRTTH\%3e2.0.CO;2

Kobayashi S, Ota Y, Harada Y et al (2015) The JRA-55 reanalysis: general specifications and basic characteristics. J Meteorol Soc Jpn 93:5-48. https://doi.org/10.2151/jmsj.2015-001

Kodera K, Koide H, Yoshimura H (1999) Northern Hemisphere winter circulation associated with the North Atlantic oscillation and stratospheric polar-night jet. Geophys Res Lett 26:443-446. https:// doi.org/10.1029/1999GL900016

Kodera K, Eguchi N, Ueyama R et al (2019) Implication of tropical lower stratospheric cooling in recent trends in tropical circulation and deep convective activity. Atmos Chem Phys 19:2655-2669. https://doi.org/10.5194/acp-19-2655-2019

Kornhuber K, Osprey S, Coumou D et al (2019) Extreme weather events in early summer 2018 connected by a recurrent hemispheric wave-7 pattern. Environ Res Lett 14:054002. https://doi.org/10. 1088/1748-9326/ab13bf

Lawrence DM, Webster PJ (2002) The boreal summer intraseasonal oscillation: relationship between northward and eastward movement of convection. J Atmos Sci 59:1593-1606. https://doi.org/ 10.1175/1520-0469(2002)059\%3c1593:TBSIOR\%3e2.0.CO;2

Liebmann B, Smith CA (1996) Description of a complete (interpolated) outgoing longwave radiation dataset. Bull Am Meteorol Soc 77:1275-1277. https://www.jstor.org/stable/26233278

Liu C, Zipser EJ (2005) Global distribution of convection penetrating the tropical tropopause. J Geophys Res Atmos 110:1-12. https:// doi.org/10.1029/2005JD006063

Matsuno T (1966) Quasi-geostrophic motions in the equatorial area. J Meteorol Soc Japan Ser II 44:25-43. https://doi.org/10.2151/ jmsj1965.44.1_25

Moon JY, Wang B, Ha KJ, Lee JY (2013) Teleconnections associated with Northern Hemisphere summer monsoon intraseasonal oscillation. Clim Dyn 40:2761-2774. https://doi.org/10.1007/ s00382-012-1394-0

Mori M, Watanabe M (2008) The growth and triggering mechanisms of the PNA: a MJO-PNA coherence. J Meteorol Soc Jpn 86:213-236. https://doi.org/10.2151/jmsj.86.213

Munemoto M, Tachibana Y (2012) The recent trend of increasing precipitation in Sahel and the associated inter-hemispheric dipole of global SST. Int J Climatol 32:1346-1353. https://doi.org/10. $1002 /$ joc. 2356

Nakamura H, Fukamachi T (2004) Evolution and dynamics of summertime blocking over the Far East and the associated surface Okhotsk high. Q J R Meteorol Soc 130:1213-1233. https://doi. org/10.1256/qj.03.101

Nicholson SE (2013) The West African Sahel: a review of recent studies on the rainfall regime and its interannual variability. ISRN Meteorol 2013:1-32. https://doi.org/10.1155/2013/453521

Nicholson SE, Palao IM (1993) A re-evaluation of rainfall variability in the Sahel, Part 1. Characteristics of rainfall fluctuations. Int J Climatol 13:371-389. https://doi.org/10.1002/joc.3370130403

Nitta T (1987) Convective activities in the tropical western Pacific and their impact on the northern hemisphere summer circulation. J Meteorol Soc Jpn 65:373-390. https://doi.org/10.2151/ jmsj1965.65.3_373

Nitta T, Hu ZZ (1996) Summer climate variability in China and its association with $500 \mathrm{hPa}$ height and tropical convection. Meteorol Soc Jpn 74:425-445. https://doi.org/10.2151/jmsj1 965.74.4_425

Ogasawara T, Kawamura R (2007) Combined effects of teleconnection patterns on anomalous summer weather in Japan. J Meteorol Soc Jpn 85:11-24. https://doi.org/10.2151/jmsj.85.11

Ogi M, Yamazaki K, Tachibana Y (2004) The summertime annular mode in the Northern Hemisphere and its linkage to the winter mode. J Geophys Res D Atmos 109:1-15. https://doi.org/10.1029/ 2004JD004514

Ogi M, Yamazaki K, Tachibana Y (2005) The summer northern annular mode and abnormal summer weather in 2003. Geophys Res Lett 32:1-4. https://doi.org/10.1029/2004GL021528

Otomi Y, Tachibana Y, Nakamura T (2013) A possible cause of the AO polarity reversal from winter to summer in 2010 and its relation to hemispheric extreme summer weather. Clim Dyn 40:1939-1947. https://doi.org/10.1007/s00382-012-1386-0

Rodríguez-Fonseca B, Mohino E, Mechoso CR et al (2015) Variability and predictability of west African droughts: a review on the role of sea surface temperature anomalies. J Clim 28:4034-4060. https://doi.org/10.1175/JCLI-D-14-00130.1

Rodwell MJ, Hoskins BJ (1996) Monsoons and the dynamics of deserts. Q J R Meteorol Soc 122:1385-1404. https://doi.org/10. 1256/smsqj.53407 
Rodwell MJ, Hoskins BJ (2001) Subtropical anticyclones and summer monsoons. J Clim 14:3192-3211. https://doi.org/10.1175/15200442(2001)014\%3c3192:SAASM\%3e2.0.CO;2

Sardeshmukh PD, Hoskins BJ (1988) The generation of global rotational flow by steady idealized tropical divergence. J Atmos Sci 45:1228-1251. https://doi.org/10.1175/1520-0469(1988)045\% 3c1228:TGOGRF\%3e2.0.CO;2

Sato T, Nakamura T (2019) Intensification of hot Eurasian summers by climate change and land-atmosphere interactions. Sci Rep 9:1-8. https://doi.org/10.1038/s41598-019-47291-5

Schumacher C, Houze RA (2003) Stratiform rain in the tropics as seen by the TRMM precipitation radar. J Clim 16:1739-1756. https:// doi.org/10.1175/1520-0442(2003)016\%3c1739:SRITTA\%3e2.0. $\mathrm{CO} ; 2$

Schumacher C, Houze RA, Kraucunas I (2004) The tropical dynamical response to latent heating estimates derived from the TRMM precipitation radar. J Atmos Sci 61:1341-1358. https://doi.org/ 10.1175/1520-0469(2004)061\%3c1341:TTDRTL\%3e2.0.CO;2

Tachibana Y, Iwamoto T, Ogi M, Watanabe Y (2004) Abnormal meridional temperature gradient and its relation to the Okhotsk high. J Meteorol Soc Jpn 82:1399-1415. https://doi.org/10.2151/jmsj. 2004.1399

Tachibana Y, Nakamura T, Komiya H, Takahashi M (2010) Abrupt evolution of the summer Northern Hemisphere annular mode and its association with blocking. J Geophys Res Atmos 115:1-13. https://doi.org/10.1029/2009JD012894

Takaya K, Nakamura H (2001) A formulation of a phase-independent wave-activity flux for stationary and migratory quasigeostrophic eddies on a zonally varying basic flow. J Atmos Sci 58:608-627. https://doi.org/10.1175/1520-0469(2001)058\%3c0608:AFOAPI\% 3e2.0.CO;2
Wakabayashi S, Kawamura R (2004) Extraction of major teleconnection patterns possibly associated with the anomalous summer climate in Japan. J Meteorol Soc Jpn 82:1577-1588. https://doi.org/ $10.2151 /$ jmsj. 82.1577

Wang B, Wu R, Fu X (2000) Pacific-East Asian teleconnection: how does ENSO affect East Asian climate? J Clim 13:15171536. https://doi.org/10.1175/1520-0442(2000)013\%3c1517: PEATHD\%3e2.0.CO;2

Watanabe M, Kimoto M (2000) Atmosphere-ocean thermal coupling in the North Atlantic: a positive feedback. Q J R Meteorol Soc 126:3343-3369. https://doi.org/10.1256/smsqj.57016

Wheeler M, Kiladis GN (1999) Convectively coupled equatorial waves: analysis of clouds and temperature in the wavenumber-frequency domain. J Atmos Sci 56:374-399. https://doi.org/10.1175/15200469(1999)056\%3c0374:CCEWAO\%3e2.0.CO;2

Yang J, Liu Q, Xie SP et al (2007) Impact of the Indian Ocean SST basin mode on the Asian summer monsoon. Geophys Res Lett 34:1-5. https://doi.org/10.1029/2006GL028571

Yasunari JTH, Nakamura KMK, Choi N, Lee MI, Tachibana Y, Silva AMD (2021) Relationship between circum-Arctic atmospheric wave patterns and large-scale wildfires in boreal summer. Res Lett Environ. https://doi.org/10.1088/1748-9326/abf7ef

Publisher's Note Springer Nature remains neutral with regard to jurisdictional claims in published maps and institutional affiliations. 